\title{
OVER DE VORMVERANDERINGEN VAN HET LIDWOORD IN HET TONTEMBOAN
}

\author{
Door A. BOLSIUS S. J.
}

Toen in 1892 eenige mededeelingen over het Tou-u m-bulu door mij gepubliceerd waren in ,de Studien" (jaargang 28, dl. 45), had ik gelegenheid aan den Inlandschen leeraar der Hoofden-school te Tondano, J. Worotikan, een exemplaar van dat stuk ter hand te stellen, met verzoek, schriftelijk zijne bemerkingen daarop te willen mededeelen.

In 't midden latend of het verschillende talen, dan wel dialecten waren, gaf ik op dat er Tou-um-bulu, Tou-unsea, Tou-u-lour, Tou-um-pakěwa en de taal der Bantik gesproken werd. - Hierbij werd aangeteekend het navolgende:

«Toumbulu is (afgeleid) van Tou 'm wulur = bergbewoners; in den tijd van 't kannibalisme bewoonden zij bij uitnemendheid de bergen.

Tounsea: menschen die een zijweg gevolgd hebben, volgens legenden.

Toulour $=$ meerbewoners.

Toumpakěwa is van Tou um pakěwa.

Paǩwa $=$ een wild houtsoort met eetbare vruchten ter grootte van een kippenei; eene interessante legende bevestigt deze naamgeving.

Die 4 genoemden zijn dialecten, omdat ze heel weinig verschil hebben in grammatica.

Hierbij moeten nog komen: 1. 't Bantik-sch, en 2. 't Bentenan-sch; deze twee komen overeen. 3. 't'Ponosakan-sch, van Mongondo-sch; en 4. 't Tonsawang-sch, een mengelmoes van die andere dialecten te zamen.»

De door mij opgegeven getallen verbeterend, komt Worotikan tot de slotsom, dat het Toumpakěwa gesproken wordt door ongeveer juist evenveel inwoners der Minahasa als er Toumbulu — sprekende zijn. - De absolute cijfers 
van voor 20 jaar zullen wel aangegroeid zijn; de verhouding zal vrijwel nog dezelfde zijn gebleven.

De naam Toumpakěwa is sinds een tiental jaren overgegaan in Tontemboan, zoo als we het voortaan zullen noemen.

(Zie betreffende die naamsverandering: Tijdschrijt voor Taal-, Land- en Volkenkunde van Nederlandsch-Indië dl. 46. De benamingen Tontemboan en Tempakěwa door Hr. Schwarz.)

In de „Hoofdstukken uit de spraakkunst van het Tontemboansch, door N. Adriani en M. L. Adriani-Gunning, den Haag, 1908", wordt de groep der eigenlijke Minahasische talen in twee ondergroepen verdeeld:

1. Tombulu, met Tonsea en Tondano (toulour zegt de Inlander);

2. Tontemboan, met Tonsawang.

Gerekend naar het aantal inwoners, die er zich van bedienen, is het Tontemboan, volgens Schrijver, de voornaamste taal; de volkstelling van 1896 gaf echter de meerderheid aan de Toumbulu-sprekenden.

Meer van belang echter is dit: de spraakkunstige bouw van het Toumbulu is zoozeer gelijk aan dien van het Tontemboan, dat eene goede spraakkunst van de eene taal een zeer goed hulpmiddel zou zijn voor het aanleeren der andere (Dr. Adriani, 1. c. bl. 2 , noot).

Het Tontemboan bezit in de vormveranderingen der beide lidwoorden een middel om den nominatief, genitief en accusatief, en ook het meervoud uit te drukken, mist daarentegen de vervoeging der werkwoorden....; deze kenmerken (ook den rijkdom aan vóór-, in- en achtervoegsels) heeft het Tontemboan gemeen met het Toumbulu en zijn naaste verwanten, (1. c. bl. 3.)

De „Proeve eener Grammatica van het Toumbulu” van Wilken-Niemann bespreekt slechts ter loops u en a, si en se, onder het opschrift: Bijwoorden, voorzetsels en andere artikelen. Bijdrage tot de kennis der Alfoersche taal blz. 89.)

Ook onder de „Hoofdstukken enz.” bovengenoemd is er geen, dat het Lidwoord behandelt.

"Omdat het niet te voorzien is, dat in den eersten tijd van eenige Minahasische taal eene spraakkunst zal worden geschreven" (1. c. blz. 1), en afzonderlijke behandeling van het lidwoord nog lang op zich zal laten wachten, en omdat toch die vorm- 
veranderingen van het lidwoord mijne belangstelling in hooge mate gaande makkten, heb ik bijeen verzameld al wat daaromtrent in „Hoofdstukken” en Tontemboan Woordenboek verspreid te vinden was.

Mijne bevindingen dienaangaande wensch ik hier mede te deelen.

Het Tontemboan heeft $\mathrm{t} w$ ee lidwoorden.

In de vormveranderingen der beide lidwoorden heeft deze taal een middel om den nominatief, genitief en accusatief, en ook het meervoud uit te drukken. (Spr. blz. 3.)

Eene uitzondering: het Tontemboan wijst den accusatief in zijn lidwoord si niet aan. (Spr. blz. 139).

Anders uitgedrukt: het teeken van den accusatief is het lidwoord in (nominatief ěn) of si (nominatief idem.) Spr. 192).

Deze uitzondering gaat ook door bij den meervoudsvorm se, zoo als blijkt uit de voorbeelden van accusatief (beginnend blz. 192, onderaan) waarbij o. a. voorkomt: si ipěngatangka 'ami se sěserra'an = dat waarmede wij gewoon zijn het wild (wilde dieren) te vangen, (blz. 193). Een bewijs daarvoor vinden we ook in dezen volzin: si sususuiěnoka i guru makaaruiěnoka-mai se toja'ang= het onderwijs des meesters zal den kinderen volkomen voldoening geven..... Deze vormen... regeeren den vierden naamval, (blz. 112.) Dezelfde blz. 112 geeft echter ook dit te lezen: è masitjola makapandei ěn e tow, vertaald: het schoolgaan maakt de menschen door en door knap.

Deze vormen, beschouwd als werkwoords vormen met het prefix maka- in zijn transitieve beteekenis, regeeren den $4^{\text {en }}$ naamval,» (dus: e tow $=$ de menschen is accusatief; alzoo wordt accusatief zoo wel gelijk aan genitief als aan nominatief.) "Waar zij den $2^{\text {en }}$ naamval regeeren, zijn zij op te vatten als de onder Nr. 7 genoemde samenstellingen met maka-, dus: makapandeiěn e tow, knapheid bevattende voor de (sic) menschen.» (Spr. blz. 112.)

De nominatief $\check{\mathrm{n}}$ van het lidwoord is in het Tontemboan Woordenboek niet opgegeven; men vindt daar sub $\breve{E}, 2$. opgeteekend: ¿, betrekkelijk voornaamwoord of lidwoord, al of

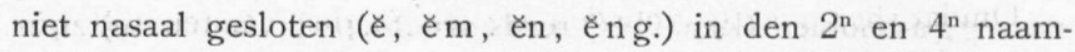
val i (im, in, ing.) meer onbepaald aanwijzend dan si. (Woordenboek blz. 34.)

1. $\mathrm{i}$, tweede naamval van het bepalend lidwoord $\mathrm{si}$; staat 
ook als naamvalsteeken tusschen den passieven vorm en den agens.

2. i, (het hier gezegde heeft alleen betrekking op persoonlijke voornaamwoorden).

3. i, al of niet gevolgd door een nasaal, genitief van het lidwoord e. Evenzoo (staat i) tusschen den passieven vorm en den agens.

Idem. Accusatief van het lidwoord e. (blz. 65-66.)

si, aanwijzend en betrekkelijk voornaamwoord, of lidwoord, voor namen van levende wezens, en van onbezielde voorwerpen, die reeds bekend of genoemd zijn. (blz. 439.)

se, meervoudsvorm van het lidwoord si. (blz. 433.)

3. e, lidwoord, meervoudsvorm van $\mathrm{i}$, tweede naamval van se. (blz. 48.)

In een kort overzicht kan dit alles op deze wijze worden weergegeven :

Lidwoord, onbepaald, enkelvoud: nominat. е $(\mathrm{m}, \mathrm{n}, \mathrm{ng}$. genit. $\quad i(m, n, n g$. accus. $\quad i(m, n, n g$.

bepaald, enkelvoud: nominat. si.

genit. i.

accus. $\quad=$ nomin. si.

meervoud: nominat. se.

genit. e.

accus. $\quad=$ nomin. se.

$\mathrm{Na}$ dit overzicht van het lidwoord en zijne veranderingen, in abstracto, kan het niet anders dan zeer nuttig zijn, de toepassing dezer regels in concrete voorbeelden na te gaan.

Eenige wijdloopigheid, waar ze noodig schijnt om de bedoeling goed te doen verstaan, houde men ons ten goede.

Woorden van deze samenstelling: prefix $\mathrm{ka}$ - in verbinding met verdubbelden stam en pron. pers. $3^{e}$ p. ( $-\mathrm{n}$ a of $\left.-\mathrm{a}\right)$ hebben de beteekenis: de toestand, respectievelijk handeling, door het grondwoord uitgedrukt, als bereikt, - als volkomen. (Spr. blz. 101, waar ook de hier volgende voorbeelden zijn gegeven.)

1. kawowo-wowosao in tjawilei "de tijd waarop aan alle mang ga-boomen (kawilei) reeds vruchten rijp (wow os) zijn».

2. kawa'u-wa'unao en tambělang "de tijd waarop de geheele stam van de bamboe geschikt is om er wa'u (stof tot kleeding) van te wevens. 
3. kaе̌ga-ěgana "de tijd waarop al de bloesems (van de a rèn-palmkolf) open zijn, tevens de tijd dat men met tyferen kan beginnen.»

4. kala'u-la'una "de tijd gedurende welken men een jong meisje (la'un) is.»

5. kauwa-uwanao im bu'uk $i$ apo "als de haren van grootvader reeds overal grijs (uwan) zijn geworden.»

6. kasama-sama'nao i tjawajo "wanneer de merrie reeds goed drachtig is.»

7. katěka-těka'nao e ko'ko' "wanneer reeds overal de kippen op stok zijn gegaan ( $t$ ěka')."

8. katumpa-tumpanao e ko'ko' "wanneer reeds overal de kippen van stok zijn gevlogen.»

Van deze voorbeelden wensch ik eerst een andere vertaling te geven; 't is slechts een vorm-verandering, om gemakkelijker over den genitief te kunnen spreken, de inhoud blijft onveranderd.

Zoo wordt dan 1. de rijpheids-tijd der kawilei, - of meer hollandsch klinkend: der pluktijd der kawilei.

2. de wa u-tijd van den bamboe (eigenlijk van een der vele bamboe-soorten).

3. de bloeitijd, hierbij is geen nadere bepaling in genitivo gegeven; duidt dit woord uitsluitend den bloeitijd van den a r è n-palm aan? Ik denk van niet. Bij a'k ǩl (arèn-palm) geeft Tt.Wdb. "De verschillende stadiën van zijn groei zijn: kaw ěruan, zie wěru; pěperr zie i.v.; longkai, zie i. v.; en posok, zie i. v.»

4. de 12-16 jarige leeftijd (kan niet van jongens gezegd worden).

5. de grijsheid van het haar van den grootvader.

6. de drachttijd der merrie.

7. de rusttijd der kippen.

8. de ontwaaktijd der kippen.

In het eerste voorbeeld vinden we in, lidwoord genit. enkelvoud; in het tweede echter lezen we ěn, lidwoord nominat. enkelvoud.

Dat het boek met de uiterste nauwkeurigheid gecorrigeerd is, blijkt duidelijk, o.a. uit het toegevoegde naschrift. We mogen er dus op rekenen dat we met een echten Tt-vorm te doen hebben.

Even zeker echter zijn we er van in de genoemde ka-vormen 
substantiva te kunnen aannemen, waarbij geen bepaling in nominativo te plaatsen is.

ka- voor stamwoorden geeft nominale vormen (Spr. blz. 95), $\mathrm{ka}$ - voor herhaalden stam van een werkwoord is te beschouwen als nominale vorm .... (ibid. blz. 99.)

"Het nomen verbale $\mathrm{ka}$ - kan in 't algemeen worden vertaald met gedoe in 't onbestemde, gepraat, geschrijf onnadenkend weg verricht.» (Spr. blz. 99.)

Onder de voorbeelden hiervan gegeven, treft men ook dit: (ib. bl. 100.) kawasa-wasaké'si toja'ang anio, vertaald door: "dat kind leest maar allerlei, rijp en groen door elkaar;" terwijl men, na de voorafgaande uitlegging, in het $\mathrm{Tt}$. den genitief $i$, en als vertaling: het er-maar-op-los-lezer. van dat kind zou verwachten. (Spr. blz. 100.)

« "Alleen bij die adjectieven, die een meetbare eigenschap uitdrukken, is uit den aard der zaak, de met ka- samengestelde vorm in beteekenis geheel gelijk aan die onzer abstracta op -heid en -te, daar "lengte, breedte, hoogte» hetzelfde uitdrukken als "mate van langheid, enz.» (blz. 96, regel 13 van boven).»»

Volgens het eenige regels te voren gezegde: "Indien ze geheel met onze zoogenaamde abstracta (op -heid of -te) overeenkwamen, dan zouden zij in genitief-verband moeten staan met het substantief, waarvan ze eene eigenschap te kennen geven (ibid. regel 6 van boven), hebben we na deze woorden een genitief te wachten.

Zeker is dit echter niet, want we lezen nog het volgende: „Zoo hebben dus kaw ěla'r (van w ělar breed), karangka' (van rangka', hoog), kakěli (van kěli, veel) niet alleen de beteekenis: hoe breed, hoe hoog, hoe veel, maar ook die van: breedte, hoogte, veelheid...... Dus: kakěli ěm bene'na! welk een hoeveelheid, zijne rijst; kakěli im bene'na, de hoeveelheid zijner rijst. (ibid. blz. 96.)

Bij dit voorbeeld mag wel eens worden verwezen naar het

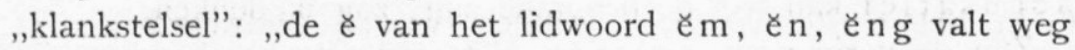
na den klinker eener open lettergreep";

en ,volgt ¿̌ op den klinker eener open lettergreep, dan houdt ze geen stand,.... een enkelen keer assimileert zij er zich mede." (Spr. blz. 13.)

en dit toepassende, gaat kakeli ěm bene'na over in kakěli m bene'na of in kakěli im bene'na. 
Bedenkt men bij dit alles dat de taal uitsluitend gesproken wordt (voor 20 jaar ging men er toe over, aan de hoofden-school te Tondano, om 2 uren per week aan onderricht in de landstaal te besteden), dan krijgt men onwillekeurig de gedachte, dat er wel evenveel uitzonderingen, als regeltoepassingen zullen gevonden worden.

Men mag niet zeggen: kaka'kat i toja'ang (de ondeugendheid van het kind); men mag wel zeggen: karěpět i Tjolano (de heftigheid van den koning); de reden van dit verschil is hierin gelegen, dat het eerste adjectief $\mathrm{ka}$ ' $\mathrm{k}$ at (ondeugend) niet, - het tweede répět (heftig) wèl eene meetbare eigenschap uitdrukt. (Spr. blz. 96.)

Op blz. 105 van de Spr. staat het volgende: kalingaano i Tjolano, en als vertaling: khet kwam gehoord te worden door den Koning».

In welken naamval staat nu «i Tjolano»?

Volgens de vorm-verandering van het lidwoord hebben we een genitief, of een accusatief; volgens de vertaling zou men aan een ablatief gaan denken, hoewel men, volgens andere gegevens, dan toch a si $\mathrm{Tj}$. zou verwachten.

Zou iemand denken dat een actieve Tt-vorm bij vertaling in passief is overgebracht, dan zou , $\mathrm{i} \mathrm{Tj}$." nog nom inatief worden.

Tot deze laatste veronderstelling kan aanleiding geven de vrijheid, waarmede men dikwijls van den eenen in den anderen vorm overgaat, zelfs in gevallen, waar het er op aankomt den juisten vorm te behouden bij de vertaling, zoo als b.v.

„Voorbeelden van passieve vormen: paparojorěn i Tjipu si Towo, vertaald: de Smid joeg den Bedrieger de trap af." (Spr. blz. 91.)

Nemen we nu aan dat paparojorěn in het Tt. passief is, dan diende vertaald te worden: de Bedrieger (si Towo, in den nominatief) werd... geworpen of gejaagd; maar hoe dan de genitief $\mathrm{i} T \mathrm{Tipu}$ terecht gebracht? Van een accusatief kan wel geen sprake zijn, zou ik denken.

Zou de vorm paparojor ̌n niet eerder te beschouwen zijn als een nominale vorm, overeenkomend met hollandsche substantiva met het achtervoegsel -sel gevormd, zoo als: schepsel, knipsel, strooisel, achtervoegsel enz.?

Dan krijgt men als vertaling (die dan stijf, en onhollandsch mischien óók al, zal genoemd worden) het volgende: 


$$
\begin{aligned}
& \text { paparojoren }=\text { het werpsel } \\
& \text { i Tjipu }=\text { van den Smid } \\
& \text { si Towo }=\text { de Bedrieger (is, was). }
\end{aligned}
$$

Op deze wijze de Tt-woorden en zinnen weergevend, komt er wel niet een goed-hollandsche uitdrukking, of fraai gestyleerden volzin tot stand, maar men krijgt een beteren blik, naar ik meen, op de kracht en beteekenis der vreemde taal, in casu het Tontemboan.

Wil men nu in woorden als: schepsel, knipsel, maaksel enz., die het geschapene, geknipte, gemaakte enz. aanduiden, iets passiefs vinden, tegenover het actief, gelegen in schepper, knipper, maker en dergelijke, daar zal geen bezwaar tegen te maken zijn.

De voorafgaande vorm: kalingaano $\mathrm{i} T \mathrm{Tj}$. beschouw ik eveneens als bestaande uit een nomen en een genitief; mocht nu van hooren ook hoorsel afgeleid worden, dan was vertaling in een gelijken vorm terstond gereed. Laat ons 't hollandsch niet te veel geweld aandoen, en dan kalingaano i Tjolano weergegeven als: het ter-kennis-gekomene-door-'t gehoor van den Koning.

In de twee aangevoerde voorbeelden, die nog met vele andere kunnen vermeerderd worden, zijn de cas us der substantieven tot hun recht gekomen, zonder willekeurige behandeling der andere vormen.

Vormen, die als werkwoorden dienst doen, kunnen ook in andere functies optreden, zoo bijv.: als adjectief beteekent pělewo'an dus ,een weinig slecht”, als werkwoordsvorm ,zullende bedorven worden".

„,karěngisạ́n beteekent: afgebrand kunnen worden, en óók: de brand;

kinarěngisan beteekent: geheel zijn afgebrand, en ook: de brand, die heeft plaats gehad." (Spr. blz. 235.)

Niet willekeurig dus, zoo als ik zeide, werden de vormen paparojor ěn en kalingaan beschouwd of behandeld, maar geheel in overeenstemming met gegevens der Spr.

Potentieele, conatieve, inchoatieve, perfectieve, duratieve en nog andere beteekenissen kunnen meer op den voorgrond treden of beschouwd worden; affixen kunnen transitieve, in- 
transitieve, instrumentale, locale wijzigingen aanbrengen; dit alles, en nog meer, heeft invloed op de beteekenis der woorden. (Spr. passi m)

Eenige voorbeelden nog om aan te toonen, dat men Ttvormen en zinnen van verschillende zijden $\mathrm{kan}$, en zelfs moet beschouwen, mogen hier nog wel een plaatsje vinden.

Nemen we eens dezen volzin: (siituoka) sera tontonano i Wuntuambene' im bowolei .... (Tt. T. blz. 129. Nr. 54. Vert. blz. 179.)

Een beginneling niet alleen, maar ook ieder ander vindt hier één woord, nam. sera $=$ zij, vnw. $3^{\text {de }}$ p.mv., dat in nominativo kan staan; i Wuntu... is genit., im bowolei kan accus. of genit. zijn.

In 't hollandsch wordt dit weergegeven als: $\mathrm{n}$ a a $\mathrm{r}$ haar (volgens Spr. blz. 230: voor hen) liet W. een langen staak neder.

Vooreerst en vooral mijn aandacht vestigend op de naamwoorden (zelfstandige en persoonlijke) en de casus, redeneer ik volgender wijze:

Sera (= zij) d.w. z. de personen, die in het water lagen of in het water dreven, zijn a nleiding, reden, oorzaak van het neerlaten van een staak;

sera (= zij) duiden aan, en vormen, als 't ware, de plaats, waarheen een staak dient gestoken, of neergelaten om hen uit het water te redden;

sera (= zij) is alzoo onderwerp, en staat in den nominatief.

tonton-an $=$ neerlaat-plaats;

i Wuntu... = van Wuntu.... staat in den genitief;

im bowolei $=$ den of van den staak; er kunnen gronden worden aangevoerd zoowel om voor den accusatief, als om voor den genitief te pleiten.

Denkt de Minahaser hier vooral aan de handeling: staakneerlaten, dan dient de vorm als accusatief, object der handeling, beschouwd; is de gang zijner denkbeelden een andere, denkt hij vooral neerlaat-plaats, dan kan ook in den genitief de bepaling van wat-men-neerlaat gegeven worden, naast den genitief (i. W.) om aan te geven wiens neerlaatplaats bedoeld wordt.

Tontonan is door mij $\mathrm{niet}$ beschouwd als werkwoordsvorm, en ook niet door een werkwoord weergegeven; aan willekeurige 
beschouwing (of verdraaiing) behoeft dit niet te worden toegeschreven, want: ,het achtervoegsel -an, dat in het $\mathrm{Tt}$. zoowel achter den zuiveren, als achter den met voor- en invoegsels samengestelden stam wordt gevoegd, heeft, in het algemeen gezegd, plaatsaanduidende beteekenis..,.. De voor- en invoegsels die, te zamen met $-\mathrm{a} n$, aan een stamwoord worden gehecht, kunnen in deze beteekenis wèl wijziging brengen, maar ze niet verdringen." (Spr. biz. 224.)

De Tontemboan-volzin wordt dus getrouw weergegeven als volgt: zij (zijn) de staak-neerlaat-plaats van Wuntuambene.

Om geheel volledig te zijn, dient iets gezegd betreffende het tweede suffix van tonton, namelijk -o.

De achtervoegsels -o, -pe, -kě, -ka e. a. beteekenen: toch, slechts, maar, nog, enz.; dienen ter versterking van zin of woord, enz. Voort-zetsels, in den zin van verlengstukken, werden ze door Worotikan genoemd; als voorbeeld daarvan mag wel aangehaald worden: ,„k e', slechts, achtervoegsel, waarop dan nog dikwijls volgt: ka'i tu'u re'e, bijv. aitjawekar(๕) ke ka'i tu'u re'e $=$ is dus dan maar losgeraakt." (Tontemboan Woordenboek i. v.)

Si Sokope'sairianoka i Tjuow, (Tontemboan Tekst, blz. 16) deze zin wordt vertaald: Sokope' wordt als getuige begeleid door deze kaneelduif. (Tontemboan tekst Vert. blz. 26). In de Spr. wordt dit weergegeven als: voor (bij) den Sokope' werd als getuige opgetreden door den Koeow. (blz. 227.)

(Koeow, met oe geschreven ter wille der lezers in Holland, denk $\mathrm{ik}$, = si Tjuow. - In het Tontemboan komt $\mathrm{tj}$ in plaats van $k$, als de onmiddelijk voorafgaande lettergreep een i-klank heeft).

Si Sokope' houd ik voor nominatief, even als Vert. blz. 26.

i Tjuow daarentegen dient, afwijkend van de twee aangegeven vertalingen, wijl het een genitief.is, ook als zoodanig weergegeven.

sairi-an is voor mij, n'en déplaise, geen werkwoord noch w-w-vorm, maar een nomen, aangevende de plaats waar (respectievelijk den persoon bij wien) iets is of geschiedt.

(Zie Studiën, jrg. 28 dl. 45, blz. 285, vlgg. - Overdr. blz. 22).

Met verwijzing naar het boven aangehaalde uit Spr. blz: 224, vertaal ik dan:

Sokope' (is) de getuig-plaats van Koeow. 
(Getuigplaats $=$ respectievelijk persoon bij wien.)

-o ka, aanhangsel, bestaande uit -o en -ka. (Woordenboek i. v.)

In "Anthropos" jrg. 1909. Bd. IV. Bibliogr. blz. 1115, heb ik aangetoond, dat -o ka volstrekt niet het futurum aanduidt, wat toch in Tontemboan-Woordenboek op blz. 291 beweerd wordt.

De zoo even aangehaalde vertalingen, uit Tontemboan-Tekst Vert. en uit Spr. kunnen wederom dienen om mijne stelling te bevestigen.

Voldoende en duidelijk naar ik meen, is door de aangevoerde voorbeelden aangetoond, dat men tot andere vertalingen, dan die in de Spr. gegeven zijn, moet komen, als men op de eerste plaats in het oog houdt de kenbare casus-vormen, en vervolgens ook door de vertaling wil doen uitkomen de eigenlijke kracht en beteekenis der Tontemboan-woorden.

In een leerboek, en op dezen titel mag toch de Spr. aanspraak maken, al omvat zij nog slechts eenige Hoofdstukken, zou een meer stijve, houterige, overzetting zeker niet misplaatst, wellicht zelfs gewenscht zijn. Verhalen en Fabelen en dergelijke, waarvan men den inhoud in ruimeren kring wil doen kennen, worden natuurlijk in meer ,genietbaar" hollandsch overgebracht.

Als voldoende reden en goede grondslag bij vertaling en verklaring van Tantemboan-vormen en zinnen, mag zeer zeker aangevoerd worden de kenbaarheid der naamvallen. Zoo noodig, zou hier beroep kunnen gedaan worden op de Spr.-zelf. Op blz. 139 toch dient juist de duidelijk-ken bare casus van het lidwoord om uit te maken of een vorm actief, dan wel passief, moet genomen worden, en: ,verwarring is hierbij uitgesloten.... . (althans bij het lidwoord е̌n) (Spr. 139.)

Bij de woorden, gevormd door prefix $\mathrm{ka}$ - in verbinding met verdubbelden stam en pronominaal suffix van $3^{\text {de }}$ persoon enkelvoud $-\mathrm{na}$ of $-\mathrm{a}$, die op blz. 4 werden aangehaald, met verwijzing naar Spr. blz. 101, moeten nog eenige bemerkingen worden toegevoegd.

Ze zijn beter geplaatst hier aan het einde, dan tusschen de casus- besprekingen van het lidwoord, die daardoor noodeloos zouden onderbroken zijn.

1. Als algemeene beteekenis van prefix $\mathrm{ka}$ - wordt opgegeven: geheel, volledig, reeds geworden zijn wat het grondwoord uitDl. 70 . 
drukt. Met betrekking tot den $\mathrm{tij} d$, heeft het de beteekenis van afgeloopen, perfectisch. (Spr. 94.)

In verbinding met sommige stammen, die tijdaanwijzende beteekenis hebben (dag, nacht, jaar en dergelijke) duidt kaaan, dat die is afgeloopen, vol, dus verleden; b. v. kawengi ,de afgeloopen nacht" enz. waarbij uitkomt de perfectische beteekenis van ka-. (Spr. blz. 98.)

De uitdrukkingen ,afgeloopen, perfectisch" en ,dus tevens verleden" brengen ons tot een perfectum, verledene tijd.

2. Daarna wordt een ander soort tij d s-aanwijzingen besproken: namelijk de woorden, samengesteld uit $\mathrm{ka-}$, herhaalde stam (die als zoodanig geen tijdaanwijzende beteekenis heeft), en het suffix - na (-a). En ook hier wordt wederom uitdrukkelijk verklaard, dat de beteekenis deze is: het door het grondwoord uitgedrukte heeft den perfectischen toestand bereikt. (Spr. blz. 101.)

De bijgevoegde vertaling plaatst echter de rijpheidstijd, bloei-tijd, dracht-tijd enz. in het praesens, niettegenstaande de herhaalde verzekering, dat men bij samenstellingen met ka- aan af, afgeloopen, dus verleden hebbe te denken.

Het volkomene (perfecte) van toestand, en het verledene (perfective) van tijd schijnen wel wat dooreen geward.

3 . Bij de vormen sub 2 . wordt aangemerkt, dat het grondwoord niet altoos herhaald wordt, zoodat bijv. ka ̌gana, katěkana eveneens bloeitijd, roesttijd beteekenen; men behoort dan echter bij de overzetting niet te zeggen, dat alle bloemen (tot de laatste) open, of alle kippen (zonder uitzondering) op stok zijn. (cf. Spr. blz. 102.)

4. Vooral het $1^{\mathrm{e}}$ voorbeeld van blz. 666 , maar toch ook 2 , 5 , 6 en 8 , geven aanleiding op de volgende bijzonderheid te wijzen.

Het Tentemboan - gelijk tal van andere Indonesische talen toont een afkeer te hebben van opeenhooping van lipklanken. (Spr. 146.)

Deze afkeer dient als verklaring van de afknotting van pumitong tot mitong; van wumuleng tot muleng, enz.

Wat zien we nu echter bij den vorm sub $1,: \mathrm{ka}$-wowowowos-a-o? - Het stamwoord is hier wowos, dat reeds twee lipletters heeft; de w toch, bij de opgave van het Ten- 
temboansch alphabeth als halfklinker aangegeven, (Spr. blz. 9) wordt op blz. 132 labiaal genoemd. - Nù is echter ,de afkeer van opeenhooping der lipklanken" niet voidoende om eene verdubbeling (wowos tot wowo-wowos) te beletten, en dat nog wel in de bijzondere omstandigheid, dat de verdubbelde vorm totaal overbodig wordt verklaard door het $\mathrm{sub} 2$ aangevoerde uit Spr. blz, 102.

5. Deze verdubbelde vormen met prefix en suffixen geven ook nog aănleiding om een woordje te zeggen over de schrijfwijze van zoo lange en veellettergrepige woorden.

Zoowel in Spr. als in Tentemboansche Woordenboeken vinden we, bij verdubbelde vormen, het stamwoord van zijne voorafgaande herhaling gescheiden door een verbindingsteeken (-). Zou het niet wenschelijk zijn, ook het of de prefixen, eveneens de affixen, door het gebruik van verbindingsteekens duidelijker te doen uitkomen?

Als men niet enkel ka-, maar nimaka- geprefigeerd, of in plaats van -n a-o (zooals bij de vormen van blz. 666) -an-erao ka gesuffigeerd vindt, dan wordt het bepaald moeielijk om zoo'n lang aanéén geschreven woord te ontcijferen.

Er zijn bovendien voorbeelden aan te halen, die de noodzakelijkheid aantoonen van het gebruik der verbindingsteekens.

Wijzen we, om iets te noemen, maar eens op Nr. 5 der vormen van blz. 666: ka-uwa-uwan-a beteekent: grijsheidstijd; vergelijken we dit met: ka-uwa-uwa'-na, dat met dezelfde letters geschreven wordt. - De wortel uwa' beteekent, even als ěga, opensnijden; de vorm ka-uwa-uwa'-na kan dus ook wel het opengaan van bloemen, of iets anders, aanduiden; - geeft in ieder geval niet den ouderdom aan, en dat is voldoende.

Zelfs bij 3-en-4-lettergrepige woorden kan de wenschelijkheid, ja noodzakelijkheid, worden aangetoond, verbindingsteekens te gebruiken ten einde verwarring te voorkomen; als voorbeelden voeg ik hieraan toe:

ka-ema'-na, van ema' (maken); ka-eman-a, van eman (gelooven); kaka'-na, zijn oudere broeder; kakan-a, zijn rechterhand; en zoo zullen er nog wel meer zijn.

Oudenbosch, Juni, 1914. 